\title{
REVIEW OF PROSPECTS FOR LOBSTER FARMING
}

\author{
E.V.Radhakrishnan
}

apture fisheries have reached a peak in production, and stock enhancement or aquaculture appears to be the only hope of meeting the ever increasing demand for high value seafood like lobsters. For aquaculture, the pressing need is to solve the dilemma of promoting expansion while at the same time demanding the development of environmentally sound technologies and farming practices (Mace, 1997). Lobsters have excellent market demand and price and especially live lobsters are the most preferred. Customers in affluent countries are ready to pay more for fresh seafood. Lobsters are exported in different forms; live, frozen tails, whole frozen, whole-chilled, wholecooked and frozen and as lobster meat. The live lobster trade increased from $1.3 \%$ during $1993-94$ to $12.7 \%$ during 2003 04 period. The foreign exchange revenue from export of lobsters alone amounts to Rs.53 crores during 2003-04. Due to the increasing demand, lobsters of all sizes are caught and marketed 
and the resource is under extreme fishing pressure. Though Government of India has brought regulation on size of export of four species of lobsters, undersize lobsters are caught in the absence of any regulation for fishing and are still exported illegally. They fetch very low price and therefore result in loss of revenue to the fishermen. These lobsters if fattened can fetch higher price and can be legally exported. Until hatchery technology is commercialized, value addition to the lobsters, is possible through short term fattening. Holding low value lobsters with a view to value adding and harvesting wild puerulii for commercial grow-out appear to be technically as well as economically feasible (Mohan, 2001).

Interest in aquaculture of lobsters has grown worldwide in recent years as the lobster fisheries in many countries are overexploited (Kittaka, 1997, Phillips and Evans, 1997). In addition, high value of live lobster (US \$40) has creased intense interest in lobster farming. Among the spiny lobsters, tropical species have more favourable characteristics and are amenable to farming conditions. Tolerance to high stocking in controlled conditions communal living without cannibalism, acceptance of pelleted feed and strong market demand are some of the characteristics, which makes lobsger as a widely accepted aquaculture species. However, for sustainable aquaculture practice, hatchery production of seeds is vital, which is yet to be achieved, though larval phase of a few species have been completed. The biological and technical feasibility of lobster farming is discussed in this paper.

\section{Fattening of low value and undersize lobsters for product enhancement}

Ongrowing wild caught seed lobsters are widely practiced in Vietnam, the Philippines and Indonesia. Farming is typically on a subsistence scale (limited by the availability of seed) although the magnitude of production in Vietnam is collectively very large (1000 tonnes annually). In Australia and New Zealand, lobster seed cannot be taken for aquaculture except under strict and limited pilot license conditions. However, there is some in sea and on 
land holding of legal size lobsters for weight gain and/or more favourable (niche) marketing. In India there being no restriction on fishing, large quantities of juveniles and undersize lobsters are caught and marketed. Though there is good potential for fattening to legal size, there is very little attempt. While some entrepreneurs have shown interest, availability of healthy, quality seed is a major constraint.

On growing involves holding undersized lobsters, which fetch low price or not accepted legally for export, for short period until they attain legal size. These lobsters could be held in tanks, ponds or cages fed with natural or artificial feed. Growth could be further enhanced remarkably through eyestalk ablation and by proper feed and water management. Since live lobsters fetch high market value, these can be marketed to targeted markets in Southeast Asian countries.

\section{Seed availability}

Among the shallow water species occurring along the Indian coast, Panulirus homarus, P. ornatus, P. polyphagus and Thenus orientalis are the most promising species. These species can be easily distinguished by the colour and morphological features. The hatchery production of $T$. orientalis has already been accomplished. The larval culture of the spiny lobster species occurring in India is yet to be successful though some headway has been made. Therefore farming or fattening of lobsters will have to depend upon either the post larvae (puerulii) or the undersized lobsters caught in artisanal gears. In India, lobsters appear as by catch in trawls operated in Maharashtra, Gujarat and Tamilnadu. The quantum of juveniles caught in trawls is low. Artisanal gears such as trammel nets, gill nets and traps are also used for fishing in inshore areas. Lobsters in gill nets and especially more than $50 \%$ of catch in trammel nets are undersized and cannot be legally exported. These are either illegally exported or consumed internally. The secondary holding centres keep the lobsters under highly stressed condition due to paucity of space 
and seawater facility and therefore the lobsters become weak and highly stressed. They may contact disease even if brought and stocked for ongrowing.

\section{Breeding and hatchery production}

Captive breeding of P.homarus, $P$. polyphagus, $P$. ornatus. P. longipes and $P$. versicolor has been achieved by different laboratories in India. Adult lobsters maintained in broodstock holding system mate and breed when optimum environmental conditions and feed are provided. Repetitive breeding is reported in P. Homarus. Juveniles of $P$. homarus and $P$. ornatus were reared to maturity in captivity and successful breeding achieved. Egg bearing lobsters procured directly from fishermen are also suitable for egg hatching and rearing. However berried lobsters procured from secondary holding centres are often infected and not suitable for hatchery operations. Phyllosoma larvae of $P$. homarus have been reared to stage 6 in 60 days. Recently larvae were reared to stage 8 in 42 days on a mixed diet of Artemia and plankton. Similarly larvae of $P$. ornatus, $P$. polyphagus and $P$. versicolor have also been reared through early stages. Significant advances have been made in Japan, Australia and New Zealand in culture of phyllosoma larvae of a number of temperate and semi-tropical species of lobsters to settlement. Japanese were the first to succeed in completing the larval phase of five temperate species and one semi-tropical species. Larvae took 132 to 319 days to complete the larval phase in different species. The number of instars was 17 for Jasus spp., 9 for Palinurus elephas has 25 (estimated) for Panulirusjaponicus. Survival ranged from 0.01 to $10 \%$. Phyllosoma larae of $P$. Cygnus and $J$. verraeuxi were also reared to settlement by the Australians and the New Zealanders. The method developed in northern Japan to culture phyllosoma larvae of five species of cool-temperate spiny lobsters combines the features of upwelling water, co-cultured microalgae and use of mussel gonad as food. The feeding behaviour of phyllosoma larvae shows that they are primarily predators. Recent work has shown that the contamination of culture water 
by microorganisms such as the fouling protozoans Vorticella sp. can greatly reduce phyllosoma survival. Feeding with fish larvae reduced the larval period by half ( 65 days) in P. elephas. However, commercial feasibility of seed production technology is still doubtful for most of the species because of the prolonged larval phase (> 300 days) and poor survival. Until hatchery technology is perfected, lobster farming will have to depend upon naturally available seeds.

\section{Collection and ongrowing of puerulii}

Spiny lobsters after completing its long larval life metamor phoses into postlarvae (puerulus), which swims towards the shore and settle in nearshore seagrass/seaweed habitats. They transform into postpuerulus and settle into benthic dwelling juvenile lobster. In the wild, levels of puerulii settlement vary depending on the species and geographic area, which also depends on the spawning stock. Commercial harvest of puerulii and early juveniles from the wild as suggested by the Australians may be possible where there is heavy settlement in the inshore habitat. However, the feasibility of such a proposal is to be examined in other areas, as there is apprehension that this will have serious long-term implications on sustainability of wild resources. Partial harvesting of puerulii from dense settlement areas is suggested as high mortality rates were experienced by juvenile lobsters between settlement and entry into the commercial fishery. This will benefit the wild resource as well as those interested in farming of lobsters. Commercial collection of southern rock lobster puerulii for aquaculture has already commenced in Tasmania. In India, studies conducted off Kovalam near Chennai show that puerulii of three species, $P$. homarus, $P$. polyphagus and $P$. ornatus settle in rocky areas. However, the intensity of settlement is not very high enough to suggest harvesting for ongrowing. There is no information on settlement density of puerulii anywhere along the Indian coast. 
Indian lobster fishery is poorly managed as this is a low volume resource and therefore fishing regulations are not strictly enforced. Destructive gears like trammel nets operated in inshore areas bring in large quantity of juveniles and sub adult lobsters which fetch only low price. The undersized lobsters procured from the fishermen were exported until the Ministry of Commerce and Industry, Government of India notified Minimum Legal Size (MLS) for export in 1997. Illegal export of lobsters below the MLS is still in vogue. Since there are no regulation for fishing lobsters in any maritime state, fishermen continue to bring the lobsters entangled in the nets and sell it to exporters. Nearly 50\% of the lobsters caught in trammel nets are undersized. In Gujarat, gill nets operated in the reef areas also bring undersized P.polyphagus, which are sold, for a very low price. Along the southwest and east coast of Tamilnadu, an estimated 25 tonnes of undersized lobsters are landed annually. By catching these undersized lobsters, the total loss of revenue to the fishermen is to the tune of several crores The MLS for P. homarus is $200 \mathrm{~g}$ and for P. polyphagus 300 $\mathrm{g}$ and those below the MLS, which are prohibited from export, can be fattened to the legal size and fetch higher price.

Collection, maintenance and transportation of juveniles

Fishermen either keep the lobsters in wet sand until the traders come and pick it or sell it to local merchants. These traders either keep them in holding tanks with recirculation facility (most of them with inadequate water reuse facility) or keep them in cages kept in rock pools until collected by the exporters. Since only larger lobsters with high price are given more care, the undersized low price lobsters are kept under high stress in very poor quality water. Therefore they are weak and are easily susceptible to diseases. They are unsuitable for fattening purposes. When there are transported to long distances they become further weak and on stocking dies gradually. The green colour of the lobster is lost and their shell becomes reddish in colour, which is indicative of 
stress. If the undersized lobsters should be useful for fattening, fishermen and traders should follow certain protocols so that they could supply healthy seed to the entrepreneurs. Juveniles are especially susceptible to stress and therefore they should be kept in water soon after they are brought to the shore. It is better to keep them buried in cool moist sand in shade rather than keeping at high densities in poor quality water. Maximum care should be taken so that their appendages are not lost while removing from the net or they are not injured below the abdomen. During holding in unhealthy condition they are infected by deadly pathogens through these injuries and there are instances of high mortality due to infection by pathogenic bacteria.

Fattening in land-based holding systems

Lobsters can be successfully held and fattened in land-based holding systems provided suitable environment is provided. Critical environmental parameters include the concentration of dissolved oxygen, ammonia, nitrite and carbondioxide. Nitrate concentration, $\mathrm{pH}$, salinity and alkalinity levels within the system are also important. In flow through systems, the main limiting factor is dissolved oxygen. The requirement of oxygen will be high during molting and soon after feeding. Both the process normally takes place during night and optimum levels of oxygen shall be maintained during night to avoid oxygen depletion and mortality. Oxygen related stress would adversely affect growth significantly. Unlike shrimps, lobsters are oxygen conformers and may not show any sign of low oxygen conditions, as they are capable of adjusting the metabolism even at very low levels of oxygen. Sufficient water needs to be pumped through or the water needs to be aerated to ensure lobsters are supplied with sufficient oxygen. Sudden salinity fluctuation during rains is a serious situation and in such circumstances salinity, alkalinity and $\mathrm{pH}$ should be adjusted in a reservoir, before the water is pumped in. though lobsters can tolerate gradual changes in salinity to a limited range, sudden dilution can lead to stress, 
susceptibility to disease and mortality. Tolerance limits for various water quality parameters is given in Table. 1 .

\section{Indoor tanks}

Two main systems are currently being used for fattening lobsters: flow-through and recirculating. In flow through systems, the water that is pumped into a tank is used only once. Water flow is to be decided based on the stocking density and feeding intensity. The incoming water is to be free of sediments and should have water quality parameters required for lobster farming. The water should be regularly monitored to avoid wide fluctuations in environmental parameters. In recirculating systems, the majority of the water is re-used after each pass through the tanks, first being treated to remove waste products before being returned to the tanks. Even though initial set up costs may be higher, there is an increasing interest in the use of recirculating systems. In recirculating systems also the main limiting factor is dissolved oxygen: however, the unionized ammonia concentration becomes increasingly important, and is probably the next important limiting factor. Ammonia should be removed from the system at a rate equal to the rate of production to maintain safe concentration. All recirculating systems remove waste solids, oxidize ammonia and nitrite, remove carbon dioxide, and aerate the water before returning it to the fattening system. Solid wastes can be removed by mechanical filtration, ammonia and nitrite by biological filtration and carbon dioxide by the provision of an air/water interface. The safe level of ammonia for holding lobsters is $<2 \mathrm{mgL}^{-1}$. The flow rate calculations must be adjusted according to the species held, size of the animals, the rate of feeding and the holding temperature. The required estimated flow rate in a tank holding $10000 \mathrm{~kg}$ of $500 \mathrm{~g}$ fed J. edwardsii lobsters at $13 \% \mathrm{C}$ is $4500 \mathrm{~L} \mathrm{~h}^{-1}$. The water management schedule and monitoring frequency of environmental parameters is shown in Table 3. 


\section{Tank design}

Raceways, rectangular, square or circular tanks can be used. The most preferred are individual raceway tanks. Circular or square tanks made of brick and cement or concrete are also good. Square tanks will save space when compared to circular and are also less expensive as they could be connected serially These tanks will be difficult to clean and feed the lobsters. Raceways are easier to maintain and with proper slope, the wastes can be easily removed through the outlet pipe fixed at the end of the tank. For complete removal of water, the standpipe can be lifted. Square and circular tanks will have a central drainage system or a selfcleaning two way waste removal system by which both suspended and settled wastes can be automatically flushed out of the tank. The wastes can be concentrated towards the centre of the tank by creating a vortex by the incoming water. This tank design is used in flow through systems. For recirculating system the wastewater flowing out of the tank is recirculated after removing the waste products and will be a continuous process. Since lobsters grow fast in subdued light, tank covers have to be provided to avoid bright sunlight.

\section{Stocking density}

Undersized lobsters procured from secondary holding centres transported to the fattening facility may be kept under quarantine for 48 hours to relieve the lobsters from stress. The quarantine facility should be away from grow out tanks. Healthy lobsters may be stocked at $1.0-1.25 \mathrm{~kg} / \mathrm{m}^{2}$ after segregating into different size groups. The difference in weight between the lower and upper size should not be more than $20 \mathrm{~g}$. Hideouts provided in the tank will help them to congregate around the shelter during day and prevent them from continuously moving in the tank spending lots of energy. Lobsters feed on variety of natural and artificial feed making them suitable for farming. The natural feed includes mussels, clam, squid, trash fish, and smaller crabs and shrimp meat. Artificial includes shrimp pellets that are 
suitable for juveniles and subadults. Lobsters feed actively after dusk; feeding during night will reduce feed spoilage and waste.

In Florida, Panulirus argus weighing 300-400 g held in captivity molted every 50-60 days and attained an average increase in bodyweight of $40 \%$ and is reported to obtain $60 \%$ return on investment. Table 2 shows percent postmolt weight increase and intermolt period (days) of spiny lobsters held in recirculating seawater systems at a constant temperature of $29^{\circ} \mathrm{C}$ with $12: 12$ light:dark cycle (Lellis and Russel, 1990). Juveniles of P. ornatus stocked at $43 / \mathrm{m}^{2}$ showed good artificial feed acceptance (>75\%), biomass production $\left(4.7 \mathrm{~kg} / \mathrm{m}^{2}\right)$ and good growth rate (SGR $1.56 \%)$. It is estimated that a weight increase of $1 \mathrm{~kg}$ is possible in less than 18 months. Juveniles of $P$. homarus in South Africa have attained $60 \mathrm{~mm}$ CL in 18 months. In India puerulii of $P$. homarus have been reared to $250 \mathrm{~g}$ in 18 months at Kovalam Field Laboratory of CMFRI. P. homarus weighing $80 \mathrm{~g}$ stocked in self cleaning indoor system at Calicut attained $330 \mathrm{~g}$ in 12 months with an FCR ranging from 3.5 to 4.0 on feeding with an exclusive diet of green mussel. The minimum exportable weight of $200 \mathrm{~g}$ was obtained in 130 days (Radhakrishnan, 2004). Another study in indoor grow out system at Tuticorin showed $172.7 \mathrm{~g}$ weight increase in juvenile $P$. homarus in 150 days. In Taiwan, wild caught animals stocked at $2 \mathrm{~g}$ mean weight reach $330 \mathrm{~g}$ in 16 months in small $200 \mathrm{~m}^{2}$ ponds. A fourty growth study on P.polyphagus conducted at Northern Territory University showed lobster juveniles grew substantially to $148.5 \mathrm{~g}$ in nine months.

Growth enhancement of juvenile lobsters by eyestalk ablation has been demonstrated in $P$. Homarus, $P$. ornatus and $P$. versicolor. The ablated $P$. homarus gained a weight gain of three to seven times more than the normal. In P. ornatus, $100 \mathrm{~g}$ lobsters attained $1.5 \mathrm{~kg}$ in 8 months. However, food consumption and mortality is higher in ablated lobsters when compared to normal.

\section{Lobster culture in intertidal pits}

Fattening of $P$. polyphagus was carried out in intertidal pits along the Bhavnagar coast of Gujarat during early 1990s 
(Sarvaiya, 1991). The pits are dug in the limestone intertidal areas and are of varying dimensions. No standardized stocking or feeding regimes were followed. 3000 numbers of lobsters weighing 30-50 g were stocked at a stocking density of 20 lobsters/sq.m in a pit of $21 \mathrm{~m} \mathrm{x} 7 \mathrm{~m} \mathrm{x} 1 \mathrm{~m}$. the pits were covered with nylon nets to prevent lobsters from escaping during high tide. Lobsters were fed with trash fish, small crabs, marine worms and clams@10\% bodyweight and also on compounded feeds. Juvenile lobsters, which were procured at Rs. 20/kg attained 100$125 \mathrm{~g}$ in 90 days, which were sold at Rs.250/kg during 1991. The harvest of live lobsters packed in bamboo baskets are sold to exporters. The highly profitable practice was discontinued due to intensive poaching and non-availability of enough quantity of seed lobsters.

\section{Lobster culture in cages}

In Philippines lobster culture was practiced in floating cages made of nylon material. P. ornatus weighing $100-300 \mathrm{~g}$ stocked at $8 / \mathrm{m}^{2}$ attained $800-1.3 \mathrm{~kg}$ in 6-15 months. Survival for larger sizes has been more than $90 \%$ whereas in smaller juveniles of 30-80 g, survival was less than $50 \%$. Trash fish is the main feed, which is procured at US\$ 0.13-0.22 per kg. Selling price of live lobster was US \$21-31/kg; hence a wet FCR of more than 10 can still be profitable.

In Vietnam, mariculture of lobsters in floating, fixed and submerged cages were practiced in protected bays or lagoons that have a good tidal flow. P. ornatus is the main species and $P$. homarus, P. Versicolor, P. longipes and P. stimpsoni were also cultured. Floating cage is made of nylon net material with a frame and buoy and located at a depth of 10-20 m. Wooden fixed cage is normally $20-40$ sq.m and even large cages of 200400 sq.m are also used. The off-bottom cage is typically about $0.5 \mathrm{~m}$ above the seabed. This kind of cage is suitable for sheltered bays. Submerged cage is made of iron framework with a diameter of $15-16 \mathrm{~m}$. The height is $1.0-1.5 \mathrm{~m}$. the cage has a cover and a 
feeding pipe and is used for nursery rearing. Seed lobsters of about $25-30 \mathrm{~mm}$ TL are stocked (100- to 200 per cage) and grown to a size of about $50 \mathrm{~g}(10-12 \mathrm{~cm}$ TL). Lobsters are fed exclusively with either whole finfish or chopped fish or shellfish. Finfish comprised about $70 \%$ of the diet and the preferred fish is lizardfish. Feeding trash fish results in water quality problems. The total nitrogen content in the seawater exceeded the standard level for aquaculture of $0.4 \mathrm{mg} / \mathrm{L}$. Increase in cage farming and using fresh trash fish and shellfish has led to disease problems in some areas. Some common diseases are black gill disease, shell necrosis and red body. Treatment protocols followed are treatment with 100 ppm formalin for 3-5 minutes. Red tail disease has been reported in spiny lobsters, which is similar to the gaffkemia in Homarus americanus. The symptoms are lethargy, reddish colour of underside of the abdomen, spreada eagle posture during late stages, poor food consumption and mortality. The bacteria enter into the body through the injury in the abdomen and multiply in the haemolymph. Isolation of the affected individuals and oral administration of oxytetracycline through feed are protocols for treatment. Antibiotic administration is possible only during the early stages of infection. The disease is highly contagious and spreads through water.

The estimated total annual production of farmed rock lobster was about 1500 metric tones a year with a farm gate value of US $\$ 26 . / 75 / \mathrm{kg}$. The average profit margin was $50 \%$. Therefore lobster culture is a profitable industry provided adequate seeds could be collected without disturbing the wild fishery. Suitable artificial diets are to be formulated and feeding regimes established in order to succeed lobster farming in a commercial scale. Disease protection measures should be prioritized. Cage designs should be studied for improved lobster husbandry.

Preliminary experiments in cage culture of lobsters were attempted in India by NIOT, Chennai. Floating and fixed net 
cages were positioned in protected areas. Fishermen fattened juvenile lobsters caught from the wild stocked in cages. However, the feasibility of large-scale farming is doubtful, as sufficient seeds may not be available for stocking when more number of people are involved. This may also result in high fishing pressure on wild fisheries and negative impact on natural lobster fisheries.

\section{Future prospects}

All marine lobsters are highly considered as fine table food and thus are in high demand. Most wild fisheries are overexploited, with many stocks having already collapsed or catch rates closely regulated to sustain the wild fishery. For these reasons, lobsters fetch high prices. The highest price is paid for live product, chilled or frozen products bring much lower prices. Aquaculture offers the only prospects by which lobster supplies can realistically and sustainably be increased. Considerable export potential exists for live product to Southeast Asian markets. Packing and transport conditions for live shipment of lobsters are well developed and would not be a problem. Development of a successful export market would require both continuity of supply and a reasonable volume of production. However, the greatest concern is whether aquaculture production would be sustainable if recruiting seed was taken in large quantities for aquaculture.Attempts in 1970s and in late 1990s to establish large-scale intensive aquaculture of spiny lobsters in the Philippines collap-sed within a few years of establishment when seed supplies became insufficient to support the venture. In India the resource is limited to certain pockets along the coast and lobster landing is drastically declining in all the centres due to indiscriminate fishing. Therefore, before contemplating aquaculture, research is warranted to better determine the stock structures of spiny lobsters and to estimate recruitment patterns and survival rates. Such research would enable responsible fishery management policies to be put in place to ensure sustainability of the wild fishery stocks. Low intensity aquaculture of spiny 
lobsters for value enhancement and export strictly adhering to the legal procedures could be a profitable industry in some specific locations along the coast.

Table 1: Tolerance limits for various water quality parametersfor the culturable species of lobsters

\begin{tabular}{|l|l|}
\hline Parameter & Tolerance limits \\
\hline Temperature & 12 to $31^{\circ} \mathrm{C}\left(25-30^{\circ} \mathrm{C}\right)$ \\
\hline DO (\% saturation) & $\begin{array}{l}\text { Minimum } 70 \% \text { Preferably } \\
\text { above } 80 \%\end{array}$ \\
\hline Salinity (ppt) & $30-38$ \\
\hline Ammonia (mg L-1) & $<2$ \\
\hline Nitrite (mg L-1) & $<5$ \\
\hline Nitrate (mg L-1) & 100 \\
\hline PH & 7.8 to 8.4 \\
\hline Hardness (ppm) & $100-200$ \\
\hline
\end{tabular}

Table 2: Postmolt weight increase (\%) and intermolt period (days) of spiny lobster (Panulirus argus) held in recirculating system at a constant temperature of $29{ }^{\circ} \mathrm{C}$ with 12:12 light:dark cycle (Lellis, 1990)

\begin{tabular}{|c|c|c|}
\hline Initial weight (g) & Weight increase (\%) & Intermolt time (days) \\
\hline $100-200$ & 52.3 & 40 \\
\hline $201-300$ & 45.9 & 47 \\
\hline $301-400$ & 39.9 & 53 \\
\hline $401-500$ & 35.7 & 65 \\
\hline $501-600$ & 30.1 & 74 \\
\hline $601-700$ & 27.8 & 83 \\
\hline $701-800$ & 23.8 & 84 \\
\hline $801-900$ & 25.0 & 79 \\
\hline $901-1000$ & 21.8 & 91 \\
\hline$>1000$ & 24.4 & 112 \\
\hline
\end{tabular}


Table 3: Monitoring schedules for different environmental parameters

\begin{tabular}{l|l|l|}
\hline Parameters & Schedule & Equipment \\
\hline Temperature & Daily at $1000 \mathrm{hrs}$ and $1600 \mathrm{hrs}$ & $\begin{array}{l}\text { Thermometer } \\
\text { glass/digital }\end{array}$ \\
\hline Salinity & $\begin{array}{l}\text { Weekly and before adding } \\
\text { new water }\end{array}$ & $\begin{array}{l}\text { Salinity } \\
\text { refractometer }\end{array}$ \\
\hline $\mathrm{pH}$ & Weekly or during water change & $\mathrm{pH}$ meter \\
\hline Oxygen & $\begin{array}{l}\text { Weekly: (every } 2-3 \text { hrs } 0 \\
\text { when new water is added) }\end{array}$ & Oxygen probe \\
\hline $\begin{array}{l}\text { Ammonia, nitrite, } \\
\text { nitrate, alkalinity } \\
\text { and hardness }\end{array}$ & Weekly & Measuring kits \\
\hline
\end{tabular}

\section{References:}

Kitaka, J. 1997. Culture of larval spiny lobsters: a review of work done in northern Japan. Mar. Freshwater Res., 48, 923-930.

Lellis, W. 1991. Spiny lobster: A mariculture candidate for the Caribbean? World Aquaculture, 22(1): 60-63.

Lellis, W.A. and J.A. Russel. 1990. Effect of temperature on survival, growth and feed intake of postlarval lobsters, Panulirus argus. Aquaqculture, 90:1-9.

Mace, P.M. 1997. Developing and sustaining world fisheries resources: the state of the science and management. In 'Developing and sustaining World Fisheries Resources: the State of the Science and Management. Second World Fisheries Congress, Brisbane 1996: (Eds. D.A. Hancock, D.C. Smith, A. Grant and J.P. Beumer) pp. 1-20 (CSIRO Publishing; Melbourne). 
Philipps, B.F. and L.H. Evans, 1997. Aquaculture and stock enhancement of lobsters: report from a workshop. Mar. freshwater Res. 48(8): 899-902.

Radhakrishnan, E.V. 2004. Prospects for grow out of the spiny lobster, Panulirus homarus in indoor farming system. In: program and Abstracts, $7^{\text {th }}$ International Conference and workshop on Lobster Biology and Management, 8-13 February, Hobart, Tasmania.

Radhakrishnan, E.V. and M.Vijayakumaran. 1984. Effect of eyestalk ablation in spiny lobster Panulirus homarus (Linnaeus). 1. On moulting and growth. Indian F. Fish., 31(1): 130-147.

Sarvaiya, R.T. 1991. Successful spiny lobster culture in Gujarat. Fishing Chimes, 10 (11): 30-31. 